\title{
Strategy: What Universities Can Learn From Corporate Success Stories
}

\author{
Chandra Aleong, Delaware State University, USA
}

\begin{abstract}
This paper identifies the need to view strategic management and implementation with new insights from entrepreneurs and researchers who have attained and studied successful enterprises. The backdrop is the rate of disruption taking place all over the U.S. as well as globally. The objective is to understand major changes to garner ideas for more effective decision-making at universities. Case studies, articles in scholarly journals, and newspaper reports are the data used for the study. Technology, teamwork, and culture are pivotal in the intrinsic role they play in the new era of competition.
\end{abstract}

Keywords: Strategy; Disruption; Transformation; Technology; Culture; Implementation

\section{INTRODUCTION}

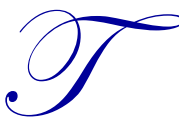

he objective of this paper is to provide a comparison between businesses and universities in the area of strategic management and implementation and to make some recommendations for future success. Higher education is in a state of flux at this juncture and is ripe for the disruption that is changing the face of almost every industry. There is a gap in the research of how higher education can reinvent itself in the face of growing technology, and especially in reimagining how learners can get more value for their dollar. The roadmap for this paper is to discuss recent case studies in the corporate arena to tease out ideas for use in higher education institutions. The theoretical models of strategic management are the backgrounds for the ensuing discussion and recommendations. An integral ingredient in fixing any problem at universities is the unique culture with the inherent importance of teamwork. Implementation, the other half of strategic management, poses major problems whether in corporate entities or universities. The main conclusions are the need for strategic planning and visionary thinking. Examples from corporate could act as a catalyst for reinventing the university environment.

Over the years there has been a continuous rethinking and reshaping of the meaning of strategy, strategic planning, strategic management as well as many other variations of similar themes. One of the most famous tools for analyzing strategy has been Michael Porter's (1979) five forces analysis framework featured in the Harvard Business Review "How Competitive Forces Change Strategy," which was widely used to analyze industry competition and attractiveness based on competitive intensity. The five forces model was externally focused and used techniques to analyze the bargaining power of suppliers and of buyers, the threat of new entrants and of substitutes, and overall industry rivalry. Business consultants and corporate planners were always looking for ways to improve their predictions and SWOT analysis credited to Albert Humphrey at Stanford University was another technique developed in the 1960s and 1970s to assist corporations in planning. The objective of strategic planning is to derive aboveaverage profit margins or value. Annual reviews of the five forces and the internal strengths and weaknesses and external opportunities and threats were supposed to enable organizations to gain a competitive advantage over their competitors. Of course, planning strategy is an art, not a science, so scholars and consultants are continually trying to improve on this very intriguing arena.

Gary Hamel and C. K. Prahalad (2005) took a different approach to strategy relative to Porter (1979, 1980, and 1985) and the SWOT team. They were internally focused, and the emphasis was on an organization's creativity over the resources it controls. Their resource-based model identified internal core competencies. They favored setting stretch targets and taking a long view of ten to twenty years out. Porter's model and SWOT analysis were considered to be too static replicating current cost and quality standards that accentuated "operational effectiveness" versus "long-term strategy." The criticism was that by focusing on current tactical advantages, planners do not see the resolution, stamina, 
and inventiveness of competitors. The backdrop was the surprising success of Japanese corporations like Toyota and Sony in surpassing American companies in the automobile, integrated circuit, and other industries. Total quality management, six-sigma, and benchmarking became the mantras that executives demanded their workers to follow.

Strategy as a separate area of research and practice assumed significant importance at the time because American companies were losing ground to competitors in the Far-East. Not only were their business processes delivering less expensive products they were also of higher quality. Scholars and practitioners were incorporating ideas from researchers in the field but also from other renowned contributors such as Henry Mintzberg and Waters (1985), Chris Christensen, (1996) and Jay B. Barney $(1986,1991)$ to name just a few of the experts in the field. However, the strategy literature, as most business thinking in the 1980s and 1990s was very "silo" oriented. Just as corporations tended to organize and strategize around major functions like finance, accounting, marketing, and R\&D, so research tended to be insular such as strategy, leadership, and entrepreneurship. Current research and thinking are more integrated and cohesive in bringing ideas from the sciences into the strategy literature.

\section{CASE STUDIES OF STRATEGIC THINKING: PIXAR \& PENN}

To understand strategy, we need to look at the organization's vision or direction and determine if there are variables that differentiate it from its competitors and give it a sustainable advantage (Cool \& Dietrickx, 1989). One example of a company where the strategy was not clear, and leadership was rudderless was Pixar during the startup years. Lawrence Levy (2016), who served as the chief financial officer, stated in a knowledge. wharton.upenn.edu/article that "they were honing this creative process and honing their technology over a long period, but it had never really come together. They had tried to make different products, different technologies, so they were like an amazing technology without a market." Levy (2016) pointed out in his book "How a Pixar CFO Learned to Love the Creative Process" that he had to find a way to help the company get a focus or broader vision. Their efforts were as follows: selling software, commercials, short films, etc. but they eventually had to drop everything and focus only on feature films such as "Toy Story." They had to harmonize the creative, technical, and business production forces to master one process rather than straddling several ventures with sub-optimum success.

Under Levy's (2016) leadership, a strategy evolved which provided an overarching trajectory for the company, instilling aspirational goals for the employees to achieve long-term sustainability. This case study exemplifies what Henry Mintzberg and James A. Waters (1985) discussed in a 1985 paper titled "Of Strategies Deliberate and Emergent." Their core idea was that deliberate and emergent strategies are two ends of a continuum along which realworld strategies lie. Levy's (2016) description of the progression suggests that Pixar had a strategy that was emerging and that it needed leadership to build a creative team and process that would be inimitable and could withstand the fluctuations of what turned out to be a new and unique business. Levy (2016) followed the following precepts for good strategy; competitive positioning, aligning people with the organization and, optimizing and restructuring for future advantage. He strengthened their value proposition and steered the company in the right direction. Pixar has succeeded in becoming a great entertainment company specializing in animated feature films. As Levy (2016) noted in a knowledge.wharton.upenn.edu/article "nobody really ever successfully created an independent animated feature film company. Even Disney over the years had long, long ago diversified away from just animation."

Having a well-honed strategy and the leadership to support, implement, and constantly reassess direction in a dynamic environment is tenuous according to Bucy, Hall \& Yakola (2016) of McKinsey (McKinsey Quarterly, November 2016) because "they (management) lack the tools and pattern-recognition experience to respond to the demands of combat." Singh and Useem (2016) in their book, "The Strategic Leader's Roadmap," recommend layered leadership, which means conveying strategic intent throughout the organization, working across layers, and having leadership invested in implementation. Not only was this the case with Pixar but another sound example of strategy with the right leadership is Amy Gutmann of the University of Pennsylvania.

The University of Pennsylvania is a good example of how successful strategy is linked to superior performance. Penn started the strategic planning process two decades ago and is an excellent case study of a higher education institution that has successfully used strategic planning and implementation for exponential growth. The strategic plan of the University of Pennsylvania (2014) which is titled Planning our Strategy for a New Century started in the 1980s when a grassroots committee examined their strengths and future challenges and based on those developed goals and 
objectives. The analysis included detailed recommendations to achieve each goal and ways to differentiate themselves from their competitors. The current president Amy Gutmann has continued the trend with Penn's commitment to the three core values in the Penn Compact; inclusiveness, innovation, and impact. Since 2009 Penn has provided \$1.4 billion in grants to low income and first-generation students. Since 2014 the Penn Center for Innovation has been fasttracking projects developed by its researchers and entrepreneurs that meet social needs. Examples of impact, the third core value, are too many and varied to name but the latest is the Joe Biden Center for Diplomacy and Global Engagement begun in 2017.

(

Small and medium-sized universities have to go through the motions of developing strategic plans for accreditation purposes. However, the process is not inclusive of the entire community, and most do not follow through with implementation, a problem not unusual to universities to be discussed later. Meanwhile, technology is playing and will continue to play a fundamental role in all industries including education. It was one of the key change drivers for Pixar and is upending every aspect of the domestic and global economy. The exponential rise and success of entrepreneurs in Silicon Valley as well as innovators like the Turners at Walden University and MOOCs are testament to this trend and demonstrates the role of strategy and leadership coalescing with technology to bring a new wave of growth.

\section{TECHNOLOGY AS A CATALYST}

\section{Corporate}

In corporate environments the term "disruption" has assumed new significance. Market conditions are moving exponentially; economic, competitive, and industry structures are being overhauled and technology is currently being employed as one of the main drivers of growth. Given this shifting landscape strategy tools need to be adjusted (Jacobides, 2010). Analytics in every aspect of business including sports and education adds a whole new dimension to the discussion of strategy and leadership. Huge amounts of information can be collected, analyzed, and disseminated enabling managers to be nimble in making strategic decisions for the short and long-term. Technology is being used to eliminate or automate steps in every process whether it is with robotics in manufacturing, the administration of online classes at the university, or even the use of the flipped classroom in the K-12 setting. The lenses through which processes are now viewed are with the goal of major transformation. In "Reinventing your business by transforming the core" Dahlstrom, Ericson, Khanna and Meffert (2017), in a McKinsey article uses Netflix as a good example of transformation, reinvention and technology. They reinvented themselves from being a renter of DVDs to being a company that streams entertainment to now creating their own content.

This process of "creative destruction," has become more prevalent across all sectors of the economy and has taken on more urgent meaning in Western economies as companies outsource jobs to India and China. Bucy, et al. (2016) in their article "Transformation with a capital T" define transformation as an intense, organization-wide program to enhance performance and boost organizational health. Internal resources must be aligned around a common vision and strategy with the impetus of incorporating digital solutions for new and sustainable sources of revenue. Management must be as open-minded as Madonna, the performer, to whom Dahlstrom et al (2017) drew a parallel as one who has had to reinvent herself several times over her thirty-year career. Average organizations and their leaders who are more accustomed to a steady pace of growth are being buffeted by encroaching technology and more significantly by new and creative ways of doing business. This requires a whole new mindset and has to begin with overhauling education in strategy, management, and the associated fields. In this "disruptive" environment, there is much scope for universities and educational organizations.

\section{Universities}

Variables at universities are not as volatile as they are in a corporate context. However, technology is encroaching on more stable market conditions and for profit and on line universities are experiencing major growth. Walden University is an excellent example of changes taking place in this market. Bernie and Rita Turner, two former New York State teachers, started Walden University in 1970 when they became frustrated by the lack of higher education opportunities available to older students and those who were already in the workforce. The Walden University (2010) webpage describes how Bernie and Rita Turner had sent out a letter to 2000 individuals about their vision for a new 
type of university. Dr. Harold "Bud" Hodgkinson, a faculty member at the University of California, Berkeley was one of those recipients. He had just published a paper titled "Walden U.: A Working Paper," a concept for a studentcentered university, that emphasized positive social change. Hodginson and the Turners got together and created Walden University. Now forty-five years later Walden University, an accredited institution, has close to 48,000 students from 150 countries and 50 states pursuing degree and certificate programs in very varied fields.

Walden is a unique example of reinvention and transformation of a university education. Overall the pace of change at universities is slow and while most universities now do strategic planning they need to rethink the structure of the entire industry and how it impacts them. Dahlstrom et al (2017) described the problem as follows: "What's often missing, ... is a comprehensive view of how an organization sets the right ambition, how to architect the right elements for the transformation, then how to systematically and holistically undertake the change journey." Given the economic and competitive environment facing higher education it is even more critical given the declines in federal and state funding. Ivy League universities are actively involved in global and technological advances to maintain and expand market share. Coursera offers more than two thousand on line courses partnering with top ranking universities like Stanford and Yale. These massive open online courses (MOOC) are aimed at unlimited participation and open access to the web. Well-financed providers, the non-profit sector, universities, related companies and venture capitalists have teamed up to create a relatively new industry that has disrupted higher education and this trend can only get bigger. The major providers are the non-profits such as Khan Academy and edX and the for-profits Udacity and Coursera. The declining ability of small and mid-size universities to raise revenue could lead to their going out of business. Even established ones like Bard College, Morehouse College, and Yeshiva University have received negative financial ratings. If they do not become creative and re-examine their missions, they will have to shut their doors.

\section{Issues with Transformation}

One of the problems with transformation is the mindset. Jennifer Mueller (2017) attests to this in her book "Creative Change: Why We Resist It ... How We Embrace It". Mueller (2017) thinks the problem is that organizations want results-driven methods that fit the metrics and forecasts. As she says, "if you believe pattern-recognition is how you find innovation, you're already lost." She says that decision-making can be better served by approaching it as an inventor, not looking at historical data since creativity comes with unknowability. Calculating risks, ROIs, or following best practices or crowds to allocate resources are wasted exercises because creativity has either weird metrics or none at all. A good example given by Mueller (2017) is the Post-it note, which was a very creative product but was not ready to be shown to a crowd. It was launched with mass advertising, showing pictures of how useful it was with little response. The administrative staff of the VPs began using them and got addicted to them, which made the VPs question why they were not getting any foothold in the mass market. Two VPs got the idea to try a different sales strategy, going to customers and showing them the product and the rest is history. The message is transformation requires creativity at every stage of the business process and especially in reinventing strategy. One major hurdle is the teamwork required for overhaul given the embedded culture of most organizations.

\section{TEAMWORK AND CULTURE}

A good example of embedded culture as a deterrent to growth is IBM in the1990s. It has been well documented in the literature that in the 1990's IBM was losing billions of dollars. Lou Gerstner (2002) was the first outsider brought in to turn things around and he stated in a Harvard Business School article that the source of the problem was cultural. "The IBM culture of crisp white shirts, hordes of administrative assistants, ... and most debilitating of the individual with a capital "I," of me-first for every employee" were very prevalent. Individualism and decentralization had served Big Blue for many years but by the 1980s and 1990s customers needed solutions to their IT problems. They needed solutions without being dependent on one company's hardware or software. This meant a move from proprietary to open standards, a policy that IBM had opposed vehemently. Gerstner's (2002) strategy was to streamline business processes and overhaul the embedded culture. His conclusion was that underneath all the sophisticated processes is a company's sense of values and identity and that culture is everything. While Gerstner (2002) saw changing culture as the defining rationale for IBM's turnaround, his insightful leadership was the catalyst for drastically altering the course of the company for future growth. 
Universities are well known for having reputations of deeply embedded cultures. The process of awarding tenure contributes to this by making it very difficult to turn institutions around. As the IBM example above shows changes were not made until there were very dire expectations for the company given its competitive environment. The same applies to higher education. Major upheavals such as the stampede of non-tenure track positions, on-line for-profit and non-profit universities, the role of the Internet as the educator of everyone and on everything, as well as attitudinal changes toward obtaining a degree due to ever-increasing cost and value are making the future of higher education institutions if not tenuous increasingly more so. While it has become fashionable to paint universities as archaic, there might be hope.

A very interesting idea for bringing university culture to the online model was described in the Wired magazine article Colleges Need to Act like Startups - or Risk going Obsolete. The authors Evan Selinger and Andrew Phelps (2014) stated that "The Golden Age of universities may be dead... It is clear that universities will have to figure out the balance between commercial relevance and basic research as well as to prove their value beyond being vehicles for delivering content. But lost in the shuffle of commentary here is something arguably more important than and yet containing all of these factors: culture. As the authors pointed out Silicon Valley would not have materialized without a Stanford and Berkeley. The cultural connection and proximity spur the creative and entrepreneurial process. The central point made is that universities are too bloated with specialized facilities that are not shared because they are so competitive with each other. The authors suggest the need to pool their resources with MOOCs, corporate entities, and others to create communities of learning. This kind of change requires visionary and strategic thinking as well as leadership to create new models that would offer educational opportunities that are high value at sensible costs. Generating this kind of thinking means finding unconventional ways of looking at entire industries.

\section{THE FIRST STEP: GENERATING STRATEGY}

Roger Martin stated in a Harvard Business article titled "The Big Lie of Strategic Planning," "If you are entirely comfortable with your strategy, there's a strong chance it isn't very good. You're probably stuck in one or more of the traps.... You need to be uncomfortable and apprehensive: True strategy is about placing bets and making hard choices. The objective is not to eliminate risk but to increase the odds of success." Martin describes the strategic planning process that entities currently practice as not the creative and tough work of developing a strategy. First, they develop a vision; next a set of initiatives; and finally, the financials to match the initiatives. Martin recommends a different three step process: first, they must try to identify the where to play (the target market), and the how to win (how to keep the customers once they have attained them). Next, they must do scenario analyses on revenue generation, a process that should reflect an emergent outlook rather than a deliberate one. The difference from the current method is the continually changing environment means modifying the data for new sources of potential revenue rather than projecting current cost and revenue streams. The last step is to make the logic of the assumptions on customers, industry, competition, and capabilities explicit. Constant and continuous rigorous review and analysis are essential for the next round of strategy generation. Lafley, Martin, Rivkin \& Siggelkow (2012), in an article "Bringing Science to the Art of Strategy" have a slightly different and interesting approach. They incorporate scientific thinking into the art of strategy. Their method emphasizes formulating well-articulated hypotheses or possibilities, which means framing the key issues and defining options or choices. The conventional approach of formulating the issues, such as loss in market share or decreasing profits and immediately collecting data detracts from the process of exploring and testing creative and innovative alternatives. Roger Martin (2014) in "The Big Lie of Strategic Planning" described conventional strategic planning as an impressionistic exercise because "planning can't and won't make revenue magically appear." While his emphasis is on finding customers and revenue, Lafley et al (2012) defined strategy generation as a seven-step approach that teams with diverse experiences should follow rigorously. The authors describe the rigor and discretion that teams should exercise to attain creative but viable solutions. First, they must frame a choice by converting the issue or issues that most urgently need to be resolved into at least two mutually exclusive options that might be solutions. Next is the process of generating an inclusive range of possibilities, which are characterized as stories that encourage discussion of the advantages, scope, and activities. The difference between conventional strategic planning and their method seems to be to waive mind-numbing and repetitive process-oriented thinking and to encourage more creative ideation. The deliberative stages of explaining why each option is strategically sound; identifying barriers; and testing for either removal or commitments must be followed thoroughly. Lafley et al (2012) demonstrated their ideas in a Proctor and Gamble (P\&G), strategic planning exercise. 
The example used was that of Olay, a $P \& G$ beauty care product. The strategic planning team came up with the idea of positioning Olay as a masstige product, meaning a product that straddles "mass market" and "prestige." It was conceived so Big-box chains and drugstores would sell products similar to the "prestige" beauty products sold at department stores. Pricing could be higher since the product would be perceived as upscale. They tested various price points to determine at which point customers would be willing to cross over from prestige department and specialty stores to buy Olay in discount, drug, and grocery stores. The price point was set to send the right message and emerged after the possibilities were researched, barriers removed, and tests exercised. Instead of "What should we do?" it was "What might we do?" The emphasis changed from looking for quick answers to asking the right questions.

With specific reference to changes that universities need to make Patrick Harker (2014), Dean of the Wharton School, University of Pennsylvania (2001- 2007), President of the University of Delaware from 2007 to 2015, and currently President of the Reserve Bank of Philadelphia has wide ranging and relevant experience to understand the current state of higher education both in the U.S. and globally. In a recent interview posted on the knowledge@wharton website and based on a scholarly paper written by Harker (2014) titled "Change Is Coming: What U.S. Colleges Must Do To Survive," he highlighted several factors that would bring higher education in line with other sectors of the economy. One interesting observation is that productivity in this sector has not increased as fast as in other sectors of the economy. He indicated that "It's not that professors are not productive; it's just that their productivity hasn't increased like we have seen in other sectors." Even with the influx of technology, the steep decline in costs has not materialized. As he shrewdly points out in a knowledge.wharton.upenn.edu/article, "Educational institutions can put in new projectors, but this does not fundamentally change the way we educate or improve productivity. Ultimately, technology alone is not going to solve the productivity problem."

With regard to strategic planning, Harker (2014) as well as well-established researchers in the field conclude that higher education is not addressing the critical problems of cost and productivity. As he says, "it's all about the curriculum" and getting economies of scale with MOOCs, online platforms, and outsourcing courses that can be commoditized. It is not about creating teaching factories, large classrooms of three hundred or more, because the teaching takes place but not the learning. Major cognitive areas that need to be incorporated in the curriculum are ideation, large-frame pattern recognition and complex forms of communication. He defines ideation as the ability to think in a visionary manner; pattern-recognition as the ability to look at an issue from several points of view, economic, political, technical, cultural etc.; and communication as understanding all the nuanced verbal and non-verbal complexities. Technology can play an integral role in the process, but it is not a panacea. His suggestion is by freeing up faculty from the more mundane duties, they can focus on areas such as mentoring, advanced seminars, and research projects. The solution requires a paradigm shift to more learner-centric rather than teacher centric solutions, which means overhauling the entire educational pipeline or process. The cornerstone for such changes rests on leadership willing to step up and assemble teams that are competent, trustworthy, and open-minded. Without these changes institutions will amble along until outside influences intervene.

\section{THE SECOND STEP: IMPLEMENTATION}

Top executives of organizations usually have the responsibility of putting together a strategic plan. It is perceived as an exercise that requires analytical and conceptual skills to set the vision for a company for five years and beyond. Execution, however, is perceived as a lower level task that is relegated to middle and lower level managers. Lawrence B. Hrebiniak (2013), of the Wharton School in his book "Making Strategy Work: Leading Effective Execution and Change" discusses the many reasons why execution is not conducted with the vigor and enthusiasm that it should receive. The factors mentioned are: the time involved; the relegation of execution to people at lower levels of the organization; the complexity due to integration of a multiplicity of external and internal variables; the lack of feedbacks and controls to keep track of meeting strategic targets and deadlines. Post audits seem dull and backwardlooking exercises and they tend to place blame rather than attribute rewards. Senior executives as well as managers want to move on to the next best thing where they would get recognition. The rewards or compensation for this part of the process are not given the importance it deserves.

Unless a culture of execution is nurtured, and implementation is rewarded, the strategic plan becomes just another exercise to satisfy the board of directors or trustees. Execution of bad strategy is unwise but good strategy must be reinforced with efficient design, rewards, and support. As Hrebiniak (2013) stated, "Failure to see and appreciate the 
interdependence or interaction among key factors - strategy, structure, controls, coordination, culture, change etc. is a costly mistake that detracts from the strategy execution success." The implementation process becomes a mindless exercise around monitoring spreadsheets with the strategic objectives, timelines, and responsible parties. While this is an important aspect of execution, incisive thinking about changes in the environment or new directions is not encouraged. Examining company culture as well as encouragement and reinforcement of behaviors related to execution, can a very important determinant in success or failure.

One of the foremost pitfalls that universities face in strategic management and implementation is the use of these processes only to satisfy accreditation requirements. There might be a strategic plan in place, but it is not considered as important in the management and execution of business, as say adhering to the rules of the tenure process or the collective bargaining agreement. When members of the faculty congregate the discussion centers around changes in federal and state funding, the curriculum, enrolment etc. These are important topics, but they are not viewed from the perspective of the three key questions of the strategic management model according to David and David (2017), as follows: "Where are we now? Where do we want to go? and How are we going to get there?" The decentralized structure of the university into colleges and departments and the governance system by committees perpetuate the reactive nature of planning. Protecting turf and legacies is the order of the day and as it is customary to say nowadays any response to criticism is met with "Stay in your lane" Or considered to be "badmouthing the institution." Fear of repercussions has led to prevalent thinking among faculty in comments such as "They want us to teach our students how to think critically but we as a faculty must not do the same." This kind of thinking is not strategic or visionary. It is provincial and short-sighted and avoids dealing with the long-term issues of sustainability and growth.

\section{CONCLUSION}

Scholars and practitioners are trying to bring rigor to the field of strategy by attempting to review and improve the theoretical models especially given the fast-moving environment of the last decade. The good news is that they are succeeding albeit with techniques like SWOT analyses, strategic plans, and core competencies becoming part of the common vernacular. Technology is a catalyst spurring new ways of viewing industries to deliver solutions. However, corporate entities do not face as many regulatory requirements as universities. At the same time, universities have the intellectual capital to solve their problems such as spiraling costs, reduced standards, outdated pedagogy and curricular offerings, etc. Most do not see the correlation between visionary and strategic thinking and improved performance. They dwell on the routine ponderous exercises required for regulation, accreditation, or review by stakeholders. The private and for-profit institutions like Penn spend their time and resources on the need to maintain their reputation or to meet shareholders' expectations.

In the final analysis, the objective of doing strategic management ultimately is to increase value, whether in for-profit or non-profit enterprises. All the case studies discussed above demonstrate that strategic management done properly leads to improved performance, whether it is Pixar, Proctor and Gamble, or the University of Pennsylvania. The lessons learnt are as follows: first there must be a clear vision of what objectives the institution is pursuing as witnessed in the Pixar case, where, initially, they were straddling several goals rather than being focused. Second, organizations need to revamp the strategic management process, which relies too heavily on looking at the past for solutions. The P\&G case, with Olay as an example, shows how new approaches to thinking can lead to successful adaptation of a current business model based on changing demographics and marketing strategies. The third lesson is the importance of having all facets of the organization aligned to a common goal. Embedded culture and lack of teamwork were instrumental in IBM's decline in the 1980's until Gerstner turned things around. The fourth lesson is the role technology is playing in transforming and disrupting entire industries. On-line universities such as Walden and the MOOC's, as well as analytics employed in every field, are prime examples of this trend. Strategic planning in every arena must incorporate technology in its bag of tools.

The catalyst for change involves a combination of inspiration and communication. As Andrew Carton (2017) described in his forthcoming article titled "I'm Not Mopping the Floors, I'm Putting a Man on the Moon": How NASA Leaders Enhanced the Meaningfulness of Work by Changing the Meaning of Work, people were so motivated, even obsessed with "putting a man on the moon," that at every level of the organization there was buy-in for this lofty vision. Universities can learn from 1960s NASA, a 400,000-person organization, on how to galvanize collective energy not only by selling the vision but showing people the connectedness of their jobs to the mission. Carton's 
(2017) description of "the social contagion effects," where one person's excitement spreads to another, led to the coordination and success of the final mission. The same can be done in every organization and just as the space race energized a whole generation, the same can be done if leaders prepare, execute, and sell their strategy.

\section{AUTHOR BIOGRAPHY}

Chandra Aleong (caleong@desu.edu) is an associate professor who teaches in the College of Education, Health and Public Policy and the College of Business at Delaware State University. She received her doctorate in Higher Education and Strategy from the University of Pennsylvania. Her research addresses issues related to education and strategy.

\section{REFERENCES}

Barney, J. B. (1986). Organizational culture: Can it be a source of sustained competitive advantage? Academy of Management Review, 11(3), 656-665.

Barney, J. B. (1991). Firm resources and sustained competitive advantage. Journal of Management, 17(1), 99-120.

Bucy, M., Hall, S., \& Yakola, D. (2016). Transformation with a capital. T. McKinsey Quarterly \& Company, November 2016.

Carton, A. (2017). Meaningful work: What leaders can learn from NASA. Retrieved from knowledge.wharton.upenn.edu/article/what-leaders-can-learn-from-nasa/.

Christensen, C. (1996). Customer power, strategic investment, and the failure of leading firms. Strategic Management Journal, 17(3), 197-218.

Cool, K., \& Dietrickx, I. (1989). Asset stock accumulation and sustainability of competitive advantage. Management Science, 35(12), 1504-1511.

Dahlstrom, P., Ericson L., Khanna S., \& Meffert, J. (2017). Reinventing your business by transforming the core. McKinsey and Company. Retrieved from www.mckinsey.com/business...mckinsey/.../from-disrupted-to-disruptor-reinventingy.Article - February 2017

David, F. R., \& David, F. R. (2017). Strategic Management: A competitive advantage approach, concepts and cases. 16th Edition, Pearson.

Friedman, T. L. (2017). Smart approaches, not strong-arm tactics, to jobs. Jan. 25, 2017. Retrieved from https://www.nytimes.com.

Gerstner, L. (2002). Changing culture at IBM - Lou Gerstner discusses changing the culture at IBM. Retrieved from http://hbswk.hbs.edu/archive/3209.html.

Hamel G. \& Prahalad, C. K. (2005). Strategic Intent. Harvard Business Review., Retrieved from https://hbr.org/2005/07/strategic-intent.

Harker, P. (2014). Change is coming: What U.S. colleges must do to survive. Retrieved from http://knowledge.wharton.upenn.edu/article/what-u-s-colleges-must-do-to-survive/.

Hrebiniak, L. G. (2013). Making Strategy Work: Leading Effective Execution and Change. (2nd Edition) Pearson Education Inc.

Jacobides, M. G. (2010). Strategy tools for a shifting landscape. Harvard Business Review, 88(1): 76-84.

Knowledge@Wharton (2017, January 20). Obama's scorecard: Hits, misses and his ongoing legacy. Retrieved from http://knowledge.wharton.upenn.edu/article/obamas-legacy/.

Lafley, A. G., Martin, R. L., Rivkin, J. W., \& Siggelkow, N. (2012). Bringing science to the art of strategy. Harvard Business Review: https://hbr.org/2012/09/bringing-science-to-the-art-of-strategy.

Levy, L. (2016). How a Pixar CFO learned to love the creative process. Retrieved from http://knowledge.wharton.upenn.edu.

Martin, R. L. (2014). The big lie of strategic planning. Harvard Business Review. https://hbr.org/2014/01/the-big-lie-of-strategicplanning.

McKinsey \& Co. (2017, January). Leading a Corporate Transformation. Retrieved from www.mckinsey.com/businessfunctions/.../our.../leading-a-corporate-transformation

Mintzberg, H., \& Waters, J. A.(1985). Of strategies deliberate and emergent. Strategic Management Journal, 6(3), Jul.-Sept., $1985,257-272$.

Mueller, J. (2017). Creative Change: Why We Resist It... How We Can Embrace It. Houghton Mifflin Harcourt.

Porter, M. E. (1979). How competitive forces shape strategy. Harvard Business Review, 57(2), March-April 1979, $137-145$.

Porter, M. (1980). Competitive strategy: Techniques for analyzing industries and competitors. New York: Free Press.

Porter, M. (1985). Competitive advantage: Creating and sustaining performance. New York: Free Press.

Selinger, E. and Phelps, A. (2014) Colleges need to act like startups-or risk becoming obsolete. Retrieved from https://www.wired.com/2014/03/universities-moocs-need-consider-culture/

Singh, H. \& Useem, M. (2016). The strategic leader's roadmap. Wharton Digital Press - University of Pennsylvania: https://wdp.wharton.upenn.edu/book/strategic-leaders-roadmap/.

University of Pennsylvania, (2014). https://stars.aashe.org/institutions/university-of-pennsylvania-pa/report/2014-05- 
01/PAE/coordination-and-planning/PAE-2/

Walden University. Celebrating 40 Years of Social Change. Walden University, https://www.waldenu.edu//media/Walden/files/.../alumni.../walden-magazine-5-2.pdf.

Welch, J., \& S. (2015). Why strong leadership is about truth and trust. Retrieved from, http://knowledge.wharton. 


\section{NOTES}

